\title{
SOME OBSERVATIONS ON THE EFFECT OF FIBROUS GLASS SURFACES UPON THE SETTLEMENT OF CERTAIN SEDENTARY MARINE ORGANISMS
}

\author{
By H. Barnes and H. T. Powell \\ The Marine Station, Millport
}

(Plate I and Text-fig. I)

The work of Wilson (I948, q.v. for further references) has emphasized the importance of the nature of the substratum for the settlement and metamorphosis of a number of marine worms, while Pomerat \& Weiss (I946) and Pyefinch (I948) have drawn attention to the effect of surface conditions upon the settlement of barnacles. Observations during some recent tests on a number of glass cloths, manufactured by Fibreglass Ltd., have resulted in further evidence concerning the marked effect of surface texture on the settlement of certain sedentary marine organisms.

Samples of these cloths were mounted on both sides of a wooden board and the latter attached to an iron frame which was suspended $2 \mathrm{ft}$. below the surface from a raft moored close inshore. Duplicate specimens of nine types of cloth were tested, the positions on each side of the board being allocated randomly. Control panels of seasoned Bakelite were exposed at the same time. (No toxic panels were under test on the raft during these exposures.)

The cloths and controls were immersed on 25 March 1949. A barnacle settlement, which subsequently developed into one of the heaviest for many years, began between I and 3 April, was heavy by the 5 th and continued for some time (Barnes, I950). At the first inspection (I5 April, 2I days' exposure) most of the cloths and the controls were heavily covered with either newly settled cypris larvae or young barnacles.

The exposure was continued and a further examination made on 9 May (45 days' exposure). Four of the samples were almost completely free from barnacles; the remainder and the Bakelite controls were more or less uniformly and very thickly covered with young barnacles, determined later to be Balanus crenatus (Text-fig. I). In marked contrast to this inhibiting effect of four of the Fibreglass panels on the settlement of barnacle larvae, all the panels and the controls were similar with regard to other attached forms, which consisted only of mixed diatom species and some short filaments of Ectocarpus sandrianus at the first inspection, with the subsequent addition of traces of Cladophora sp. and Ulothrix flacca. 
The four panels almost free from barnacles were duplicates of two types of cloth and, as a result of inquiries, Fibreglass Ltd. pointed out that these duplicates, while similar to one another, differed from the others in that they were what is termed 'staple' cloths. As such, they are made up of comparatively short lengths of glass fibre spun together to form a strand before weaving into cloth. The other samples, which had not inhibited settlement, were 'continuous' cloths, consisting basically of very long glass filaments. A microscopic examination showed the continuous cloth to have an extremely smooth surface (Pl. I, fig. I), in marked contrast to the rough spinous surface of

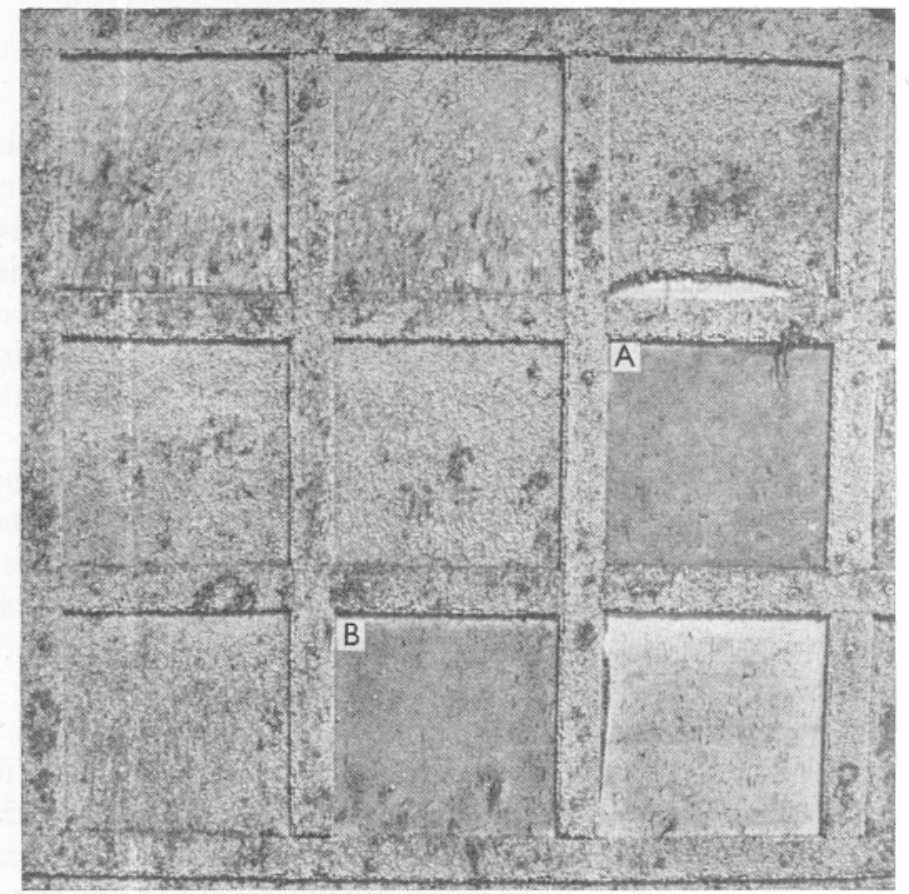

Text-fig. I. Nine samples of Fibreglass cloth after 45 days' exposure. Note almost complete absence of barnacles on the staple cloths, panels A and B. $\times \frac{3}{20}$.

the staple cloth, resulting from the projecting and partially interlocking free ends of the short, fine glass filaments (diameter $8 \mu$ approx.) comprising the individual strands. The general impression of the surface of these staple cloths was, therefore, of a stiff fibrous weft, beyond which numerous longer fibres (about $\mathrm{I} \cdot 0 \mathrm{~mm}$. in length) projected (Pl. I, figs. 2, 3).

In view of the strikingly different effect of these two types of cloth upon settlement of barnacles, a second set of panels and controls was put out on 26 July I949, to ascertain whether there was any similar effect with respect to settling forms prevalent later in the season. 
At the first inspection (I2 August, I 7 days' exposure) only diatoms and traces of algal sporelings were present on all panels and controls. After a further 6 weeks' exposure all had a heavy growth of Tubularia larynx, together with some Laomedea (Campanularia) flexuosa, and some panels had a number of newly settled Pomatoceros triqueter. At the next inspection (22 October, 88 days' exposure) it was evident that there was a clear distinction with regard to this Pomatoceros settlement. The staple cloths that had virtually prevented the settlement of barnacles were quite free from Pomatoceros which was, however, present on all the smooth cloths and frequent on some, although no cloth was as heavily covered as the control panels. Continued exposure throughout a further period of heavy Pomatoceros settlement, as clearly indicated by the control panels, confirmed the effectiveness of these staple cloths in preventing attachment of this species. The control panels showed that during this period there was a settlement of Anomia ephippium, the light character of which settlement makes confirmation of the results necessary, but examination of the cloths suggested that its settlement had been inhibited by the staple yarns.

It appears, therefore, that the texture of the surface of the staple cloth prevents the settlement of Balanus crenatus and Pomatoceros triqueter, whose larval forms differ widely in both structure and size, but is without effect on the settlement of Tubularia larynx.

Visscher (I928) states that cypris larvae, in a series of exploratory movements, may cover appreciable distances before attaching. It is possible, therefore, that during these movements the projecting bristles of the staple cloths by their number and stiff character may prove a source of irritation or may mechanically restrict such exploratory movements, either effect causing the cypris larvae to move away. It is of interest to note that settling oyster larvae are sensitive to the physical texture of the surface, and that they also carry out exploratory movements before settlement and metamorphosis (Prytherch, I934; Cole \& Knight-Jones, I939). Further, according to these authors, these larvae do move away from an unsuitable surface. It is not clear, however, why such a surface as this staple cloth presents, if actively irritating, does not prevent the settlement of the actinula larva of Tubularia, although of course the latter may be less sensitive to this type of mechanical irritation. This larva, according to Pyefinch \& Downing (I949), also moves over a surface before settling, but the length of the aboral tentacles would be sufficient to penetrate the fibrous surface weft. A similar explanation has been advanced by these authors to explain the lack of settlement of Tubularia on a surface covered by long tufts of filamentous algae, in contrast to its ready settlement on a surface covered by shorter (less than $2 \mathrm{~mm}$. in length) algal tufts. In addition, any irritation of an actinula larva may stimulate discharge of the nematocysts contained within the swollen tips of the attaching aboral tentacles, thus facilitating attachment.

Wilson (1948), working with the larva of the polychaete Ophelia bicornis, found that substrata consisting of more angular grains were unfavourable to 
settlement and metamorphosis, and he suggested that the size and shape of the interstices between the grains were more important than the grain size or shape, a critical amount of surface area being requisite for the initial attachment stimulus and subsequent metamorphosis. From this point of view the character of the surface of the staple cloth may not provide the appropriate stimulation.

The development of the actinula larva of Tubularia is much more direct than the metamorphosis of a barnacle or polychaete larva, and may not require so critical a stimulus for its initiation.

The courtesy of Fibreglass Ltd. throughout these investigations, and in particular the help of their representative, $\mathrm{Mr} \mathrm{H}$. Cameron, is acknowledged.

\section{SUMMARY}

A description is given of a glass cloth surface which prevents the settlement of larvae of Balanus crenatus and Pomatoceros triqueter, whilst not affecting that of Tubularia larynx. A number of possible causes for this are examined, and its relation to other work on the settlement of sedentary forms is briefly considered.

\section{REFERENCES}

BARNES, H., I950. A note on the barnacle larvae population of the Clyde Sea area as sampled by the Hardy Continuous Plankton Recorder. Fourn. Mar. Biol. Assoc., Vol. 29, pp. 73-80.

Cole, H. A. \& KNIGHT-Jones, E. W., 1939. Some observations and experiments on the setting behaviour of larvae of Ostrea edulis. Fourn. Cons. Int. Explor. Mer, Vol. I4, pp. 86-ro5.

Pomerat, C. M. \& WeIss, C. M., 1946. The influence of texture and composition of surface on the attachment of sedentary marine organisms. Biol. Bull. Woods Hole, Vol. 9r, pp. 57-65.

PRYTHERCH, H. F., I934. The role of copper in the setting, metamorphosis and distribution of the American oyster, Ostrea virginica. Ecological Monographs, Vol. 4, pp. 47-107.

Pyefinch, K. A., I948. Notes on the biology of cirripedes. Fourn. Mar. Biol. Assoc., Vol. 27, pp. 464-503.

Pyefinch, K. A. \& Downing, F. S., I949. Notes on the general biology of Tubularia larynx Ellis \& Solander. Fourn. Mar. Biol. Assoc., Vol. 28, pp. 2 I-43.

VISSCHER, J. P., I928. Reactions of the cyprid larvae of barnacles at the time of attachment. Biol. Bull. Woods Hole, Vol. 54, pp. 327-35.

WILson, D. P., I948. The relation of the substratum to the metamorphosis of Ophelia larvae. Fourn. Mar. Biol. Assoc., Vol. 27, pp. 723-60.

\section{EXPLANATION OF PLATE I}

Fig. I. A photomicrograph of surface and folded edge of a smooth continuous cloth. $\times 60$. (N.B. Folding has caused the slight irregularities seen along the edge.)

Fig. 2. The same of folded edge of staple cloth A. The projecting fine glass filaments have diameters of about $8 \mu$. $\times 50$.

Fig. 3. The same of surface of staple cloth B. $\times 30$. 


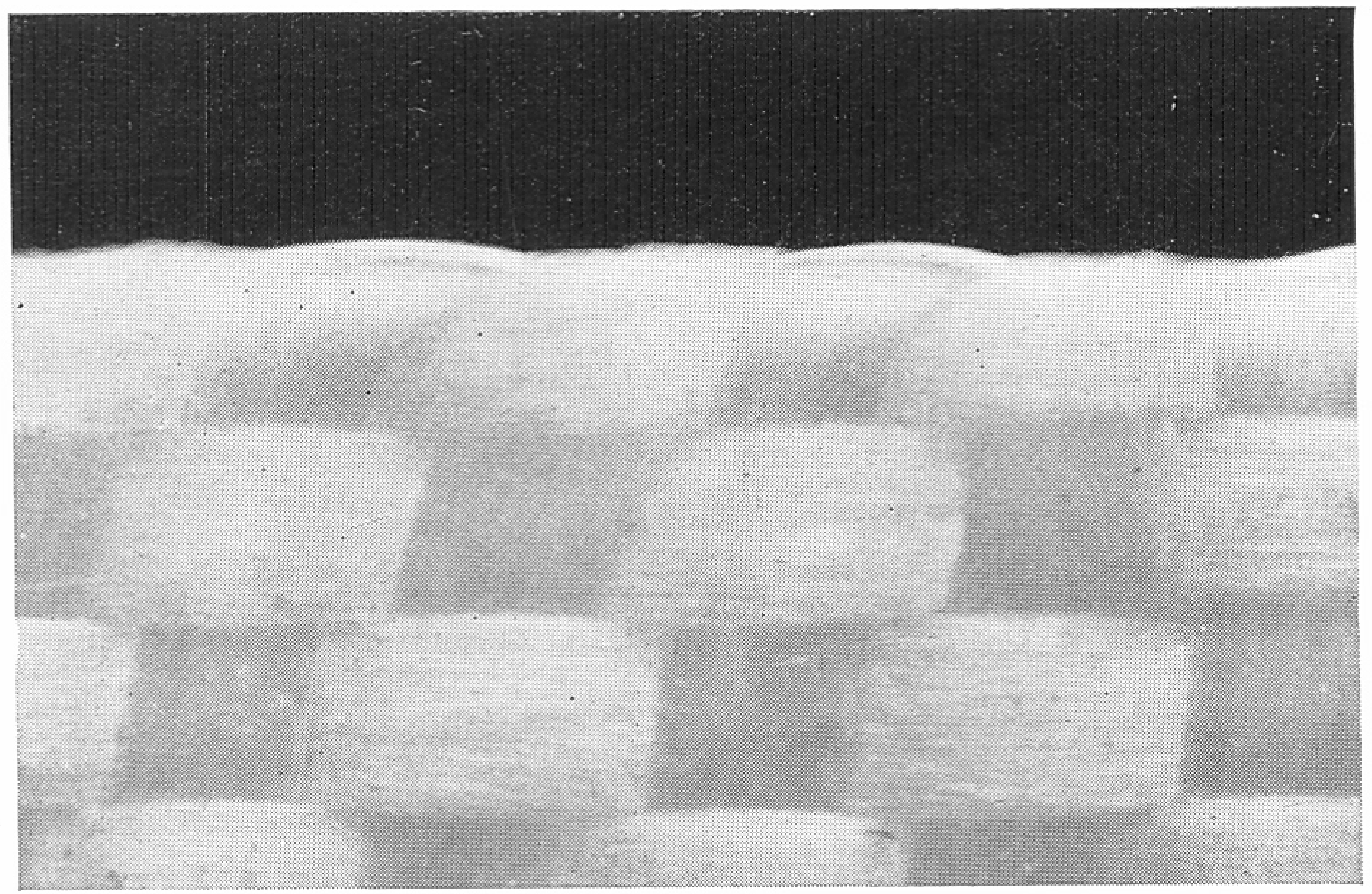

Fig. I.

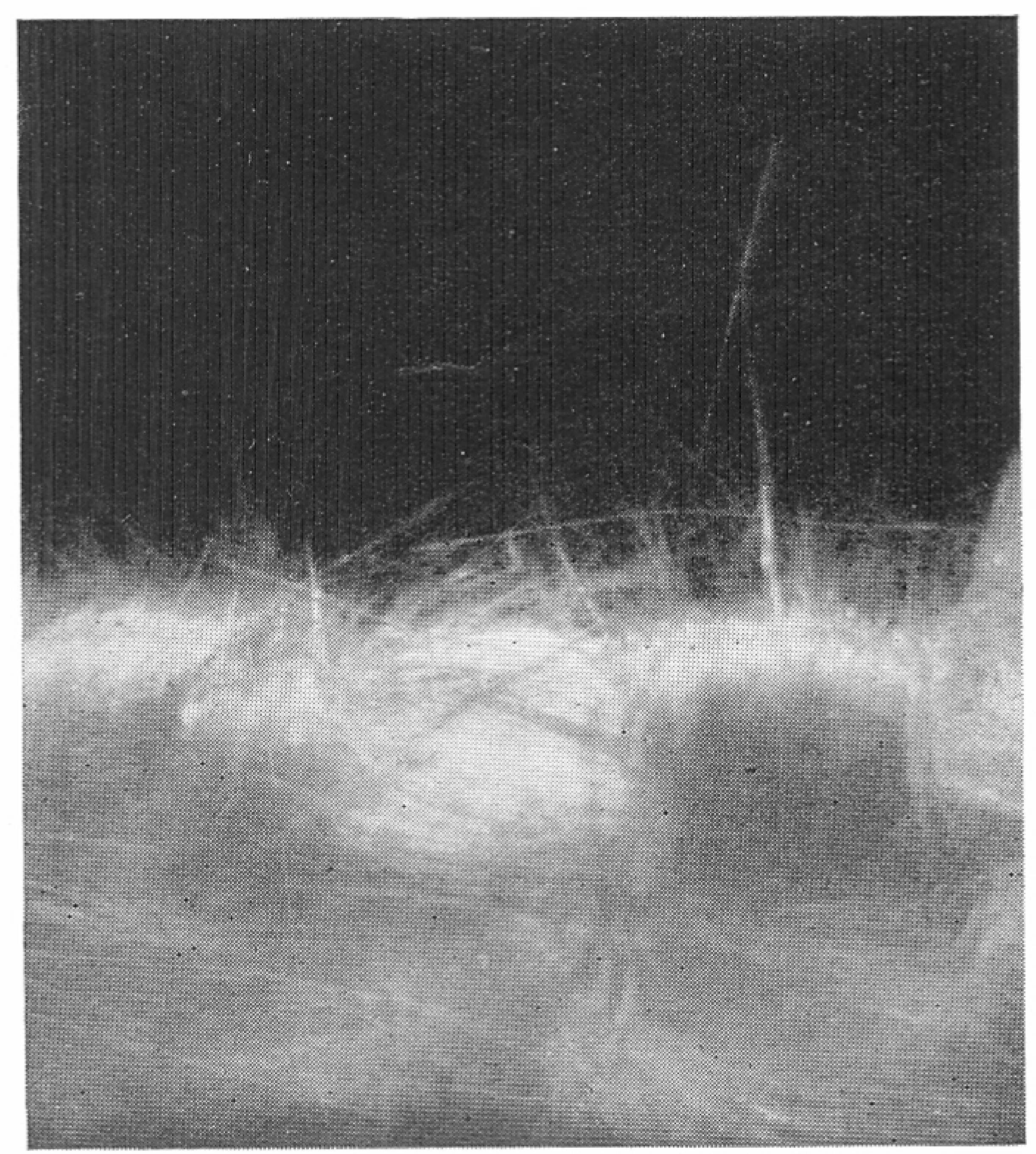

Fig. 2.

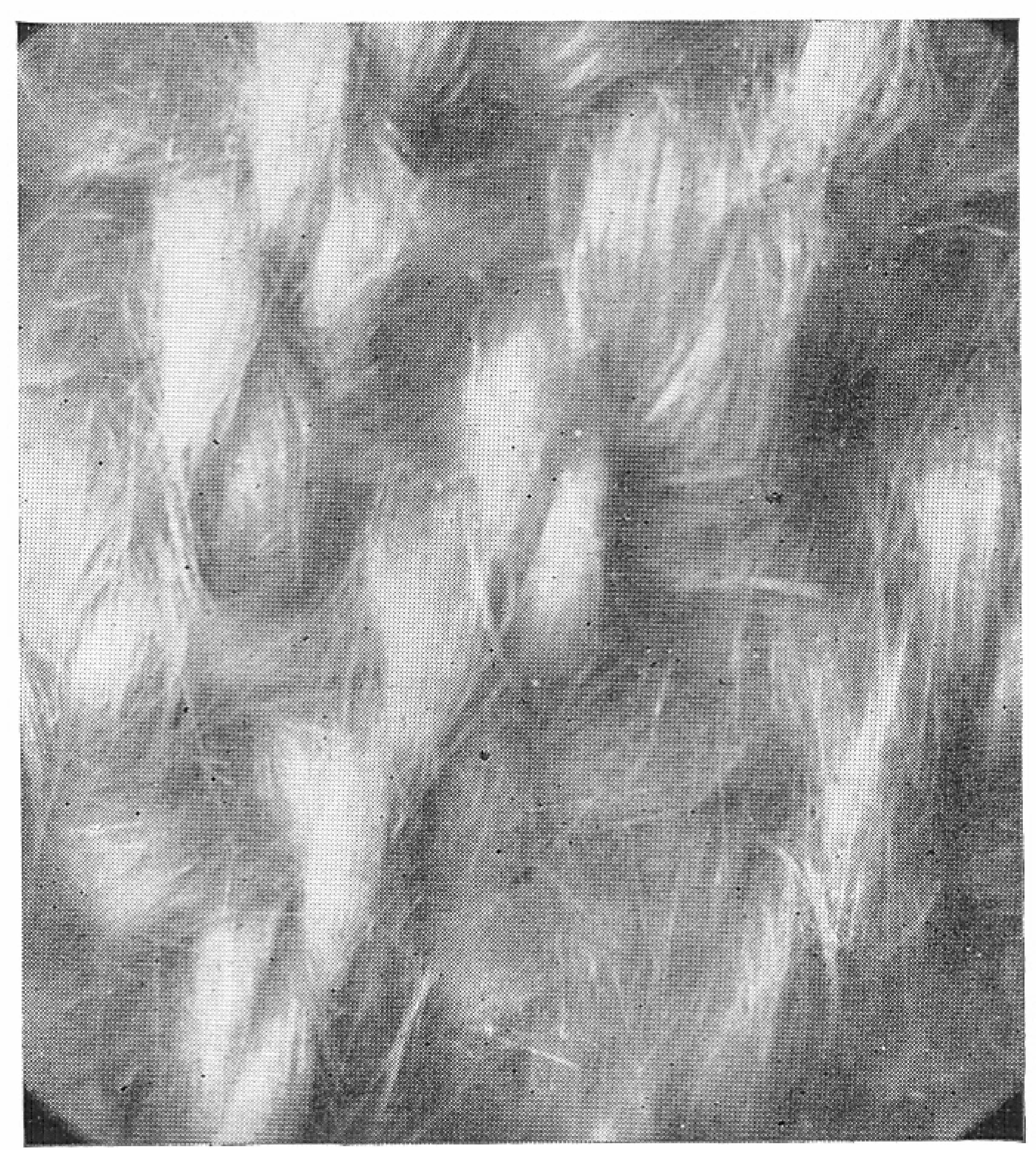

Fig. 3. 